\title{
The self-reported learning needs of primary care doctors in South Africa: a descriptive survey
}

\section{Z Malan, R Cooke \& R Mash}

To cite this article: Z Malan, R Cooke \& R Mash (2015) The self-reported learning needs of primary care doctors in South Africa: a descriptive survey, South African Family Practice, 57:1, 35-43, DOI: $10.1080 / 20786190.2014 .1002677$

To link to this article: http://dx.doi.org/10.1080/20786190.2014.1002677

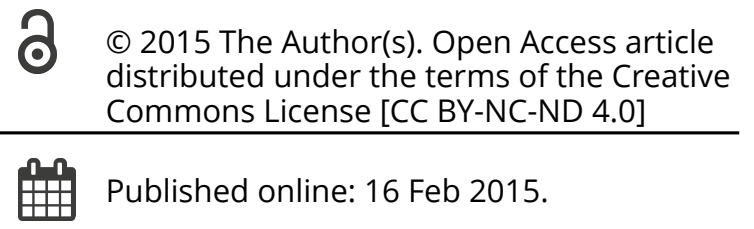

Submit your article to this journal $x$
Џll Article views: 406

Q View related articles ¿

View Crossmark data ¿

Citing articles: 3 View citing articles $\square$ 


\title{
The self-reported learning needs of primary care doctors in South Africa: a descriptive survey
}

\author{
Z Malan ${ }^{\mathrm{a} *}$, R Cooke $^{\mathrm{b}}$ and R Mash ${ }^{\mathrm{a}}$ \\ ${ }^{a}$ Division of Family Medicine and Primary Care, Stellenbosch University, Stellenbosch, South Africa \\ ${ }^{b}$ Centre for Rural Health, University of Witwatersrand, Johannesburg, South Africa \\ *Corresponding author, email: rm@sun.ac.za
}

Background: Strengthening primary health care in South Africa is a prerequisite for the successful introduction of National Health Insurance. Primary care doctors from both the public and private sectors are an essential contributor to achieving this goal. In order to prepare these doctors for their future role, a national diploma training programme is being developed. This study aimed to evaluate the learning needs of primary care doctors and to assist with the design of the diploma.

Methods: A descriptive survey of 170 primary care doctors ( 80 medical officers and 90 private practitioners), from eight provinces in South Africa, in terms of their use of 30 key guidelines, performance of 85 clinical skills and confidence in 12 different roles. Results: Doctors had read the majority of the guidelines (20/30), but few had been implemented in practice (6/30). All of the doctors had been trained in the clinical skills; however, none had taught these skills to others in the last year. Primary care doctors reported having performed the majority of the skills within the last year (70/85). Doctors had performed 7/12 roles in the last year, while $5 / 12$ had not been engaged with. The weakest roles were those of change agent and community advocate, while the strongest roles were competent clinician, capability builder and collaborator. There were a number of significant differences $(p<0.05)$ between the learning needs of medical officers and private practitioners.

Conclusion: These findings will help guide the development of a new Diploma in Family Medicine programme for South Africa.

Keywords: clinical skills, descriptive survey, family medicine, guidelines, learning needs, primary care, scope of practice, South Africa

\begin{abstract}
Introduction
Strengthening primary health care is a national priority in South Africa in order to improve equity, effectively address the burden of disease and prepare the country for the introduction of a national health insurance $(\mathrm{NHI})$ scheme. ${ }^{1}$ Currently primary care is mainly offered by nurses, with support from doctors. ${ }^{2}$ The quality of primary care is not optimal with concerns existing regarding infrastructure, supply of essential medication, capability of nurses to offer holistic and comprehensive care, and acceptability of services. ${ }^{3}$
\end{abstract}

A number of strategies to accomplish this "re-engineering of primary health care ${ }^{\prime \prime}$ have been planned and include the development of municipal ward-based outreach teams of community health workers supported by nurses and doctors, who will take responsibility for visiting specific groups of households. ${ }^{5}$ In addition the plans include strengthening of school health services, promotion of the ideal clinic and introduction of District Clinical Specialist Teams (DCST)., ${ }^{4,6}$ DCSTs consist of a group of specialists dedicated to improving maternal and child health care within a district.

A further intervention to improve healthcare within the district health system has been the recognition of family medicine as a new discipline. Since 2008 family physicians have been trained as expert generalists in new four-year programmes that model the training of other specialists. This new cadre of family physicians have begun to enter the health system and have an impact, although each province has adopted a different approach to their utilisation. ${ }^{7}$ In some provinces they have been employed at community health centres and district hospitals, while in others at the level of the sub-district, district or even regional hospital.
The numbers of family physicians are still relatively small and there is a need to create more internal policy cohesion within the Department of Health on their role and contribution. In time it is anticipated that all doctors pursuing a career in the district health services would train as a family physician.

Over the next 10-15 years, however, the pool of doctors currently working in primary care will be far larger than the number of family physicians and most are unlikely to train as family physicians, because this would mean reverting to a registrar post. The potential pool of primary care doctors includes medical officers in the public sector and general practitioners in the private sector. The Department of Health has begun to contract with general practitioners in the NHI pilot sites to bring them into the public sector primary care system. Primary care doctors will need to support all of the initiatives outlined above and in order to make their contribution will need to fulfil a number of new roles in primary health care. These future roles and competencies required of primary care doctors were identified in a national stakeholder workshop (Table 1) as part of a larger project entitled "Strengthening primary health care through primary care doctors and family physicians".

This project plans to revise the current two-year Diploma in Family Medicine that is available in South Africa, so that its learning outcomes and curriculum are better aligned with the future needs of the country and primary care doctors. Currently four universities offer such a diploma, with very different and sometimes outdated learning outcomes. The project intends that all the programmes should align themselves with the same nationally agreed learning outcomes and that new programmes should be developed at other universities so that training can be 
Table 1: Future roles and competencies of primary care doctors

\begin{tabular}{|c|c|}
\hline Role & Competencies \\
\hline \multirow[t]{4}{*}{ Competent clinician } & $\begin{array}{l}\text { The primary care doctor should be able to practise competently across the whole quadruple burden of disease They should have the clinical } \\
\text { and procedural skills to fulfil this role in primary care. }\end{array}$ \\
\hline & They should be a role model for holistic patient-centred care with the accompanying communication and counselling skills. \\
\hline & They should be able to offer care to the more complicated patients that primary care nurses refer to them. \\
\hline & They should support continuity of care, integration of care and a family-orientated approach. \\
\hline \multirow[t]{4}{*}{ Capability builder } & $\begin{array}{l}\text { The primary care doctor should be able to engage in learning conversations with other primary care providers to mentor them and build their } \\
\text { capability. }\end{array}$ \\
\hline & They should be able to offer or support continuing professional development activities. \\
\hline & They should help to foster a culture of inter-professional learning in the workplace. \\
\hline & As part of a culture of learning they should attend to their own learning and development. \\
\hline \multirow[t]{4}{*}{ Critical thinker } & $\begin{array}{l}\text { The primary care doctor is one of the most highly educated/trained members of the primary care team and as such should be able to offer a } \\
\text { level of critical thinking to the team that also sees the bigger picture. }\end{array}$ \\
\hline & $\begin{array}{l}\text { They should be able to help the team analyse and interpret data or evidence that has been collected from the community, facility or derived } \\
\text { from research projects. }\end{array}$ \\
\hline & They should be able to help the team with rational planning and action. \\
\hline & They should have IT and data management skills and the ability to make use of basic statistics. \\
\hline \multirow[t]{6}{*}{ Change agent } & $\begin{array}{l}\text { The primary care doctor should be a champion for improving quality of care and performance of the local health system in line with policy } \\
\text { and guidelines. }\end{array}$ \\
\hline & They should be a role model for change - people need to see change in action. \\
\hline & They should know how to conduct a quality improvement cycle and partake in other clinical governance activities. \\
\hline & They should provide vision, leadership, innovation and critical thinking. \\
\hline & They may need to support some aspects of corporate governance. \\
\hline & They may need to assist with clinically related administration, e.g. occupational health issues, medical record keeping, medico-legal forms. \\
\hline \multirow[t]{2}{*}{ Collaborator } & The primary care doctor should champion collaborative practice and teamwork. \\
\hline & They should help develop a network of stakeholders and resources within the community. \\
\hline \multirow[t]{2}{*}{ Community advocate } & $\begin{array}{l}\text { The primary care doctor should exhibit a community-orientated mind-set that supports the ward-based outreach teams, understands the } \\
\text { community's health needs and social determinants of health in the community and thinks about equity and the population at risk. }\end{array}$ \\
\hline & They should be able to perform home visits in the community when necessary. \\
\hline
\end{tabular}

offered at scale throughout the country. The College of Family Physicians also offers a diploma-level exam, which should be included in this revision process.

In order to re-design the diploma at a national level it was decided to survey the learning needs of existing primary care doctors relative to their anticipated future roles so that these results could help guide the process. The aim of this study, therefore, was to evaluate the learning needs of primary care doctors, in the private and public sectors, across the country, in terms of their awareness of essential guidelines, ability to perform the required clinical skills and confidence to engage with the envisaged scope of practice.

\section{Methods}

\section{Study design}

This was a descriptive survey of primary care doctors.

\section{Setting}

General practitioners (GPs) were recruited from Gauteng (Tshwane District), Northern Cape (Pixley Ka Seme District), Free State (Thabo Mafutsanyana District), Limpopo (Vhembe District), Mpumalanga (Gert Sibande District), KwaZulu-Natal (Umzinyathi District), and North West (Dr Kenneth Kaunda District).

MOs were recruited from the Western Cape, Gauteng, KwaZulu-Natal, Limpopo and Free State provinces.

\section{Sample size and sampling}

A sample size calculation suggested a minimum sample size of 220 primary care doctors would be sufficient to measure the desired variables in the questionnaire.

General practitioners were recruited from the induction and orientation workshops held by the Department of Health in each of the NHI pilot districts between April and June 2014. Each province has one $\mathrm{NHI}$ pilot district, although KwaZulu-Natal is unusual in having two pilot districts. It was anticipated that 120 GPs would be recruited. The workshops were held with general practitioners as a key pillar within the Department of Health's Primary Health Care Health Professional Support Framework. These GPs had either already contracted with or were considering contracting with the public sector to provide primary care and therefore were actively reflecting on their learning needs.

Medical officers (MOs) were recruited via the Departments of Family Medicine that were partners in the larger project (Stellenbosch University, Free State University, Pretoria University, University of Limpopo and University of KwaZulu-Natal). Each department was expected to contribute 20 medical officers giving a total of 100 . Family physicians identified medical officers from facilities within the areas served by these university departments. 


\section{Data-collection tool}

The questionnaire was constructed in terms of awareness of key national primary care guidelines, clinical skills and scope of practice, in collaboration with the NDoH's technical task team on GP contracting and primary health care.

Primary care doctors' awareness and adoption of key national primary care guidelines across the burden of disease (e.g. HIV/ AIDS, TB, emergency medicine, maternal care) was assessed. For each guideline respondents were asked to select one response on a Likert scale:

- I am not aware of/have not read the guideline.

- I have read the guideline.

- I am already implementing this guideline in my clinical practice.

- I am able to teach this guideline to other health workers.

Clinical skills relevant to primary care were extracted from the national list for the training of family physicians. ${ }^{9}$ Primary care doctors were asked to assess their ability to perform these skills by selecting one answer for each skill from a Likert scale:

- I have not had training in this skill.

- I have been trained, but have not performed this skill in the last year.

- I have performed this skill in the last year.

- I have taught this skill to others in the last year.

The scope of practice as outlined in Table 1 was assessed by asking primary care doctors to rate their confidence with performing competencies related to the six roles.' Again they were asked to rate their confidence by selecting one answer from a Likert scale:

- Not confident, i.e. I have never taken on this role.

- Some confidence, i.e. I have taken on this role in the past, but not in the last year.

- Reasonably confident, i.e. I have taken on this role in the last year.

- Very confident, i.e. I could be a role model to the primary care team.

The questionnaire was validated in terms of its construct and content with an expert panel:

- the national DOH directorate for PHC and the national technical task team on GP contracting;

- Departments of Family Medicine and Primary Care at Witwatersrand, KwaZulu-Natal, Pretoria, Limpopo, Stellenbosch, Free State, Cape Town, and Walter Sisulu University;

- The national education and training committee of the SA Academy of Family Physicians.

Once the questionnaire was revised it was piloted with three GPs from Mpumalanga and three MOs in the Western Cape to ensure its functionality.

\section{Data collection}

All GPs attending the induction and orientation workshops were asked to complete the questionnaire prior to engaging with the rest of the workshop. The questionnaire was administered by RC and his colleagues at all of the workshops from April to June 2014.

The MOs were invited by the family physicians connected to the departments of family medicine to complete the questionnaire. The questionnaire could be completed electronically and returned by email or completed in hardcopy and given to the family physician.

\section{Data analysis}

The questionnaire produced quantitative data on an ordinal Likert scale (scored 1 to 4) for each item as well as some basic demographic details. The data were analysed using descriptive statistics with the help of the Centre for Statistical Consultation at Stellenbosch University. Categorical data were reported as numbers and frequencies. Ordinal data were reported as mean scores with $95 \%$ confidence intervals and statistically significant differences between GP and MO responses were tested for by use of the Mann-Whitney U-test.

\section{Ethical considerations}

Ethical approval for the research was obtained from the Health Research Ethics Committee at Stellenbosch University (N/4/03/027) and the University of Witwatersrand (M140716). Information on the study was included with each questionnaire and consent implied by completing and returning the questionnaire.

\section{Results}

A total sample of 170 primary care doctors was obtained, which included 90 GPs and 80 MOs. The primary care doctors were distributed between the provinces as shown in Table 2 .

The mean age of primary care doctors was 41.1 years (SD 12.0) and the distribution is shown in Figure 1. The mean age of the primary care doctors differed significantly $(p<0.001)$ between MOs (36.3 years (SD 10.0)) and GPs (45.6 years (SD 12.1)). This is also reflected in differences in the year of graduation with MOs having fewer years of experience than GPs, as shown in Figure 2. GPs were more likely to have another degree (MO 7 (9.0\%) vs. GP $19(22.6 \%) p=0.018)$, but not a diploma (MO 16 (20.5\%) vs. GP 26 (31.0\%) $p=0.13$ ).

Of the whole group 99/157 (58.0\%) were male, 66/157 (42\%) were female, and MOs (32/80 (42.1\%) male) and GPs (59/90 (72.8\%) male) differed significantly $(p<0.001)$. The majority of MOs were therefore female, while GPs were mostly male.

Table 2: Distribution of respondents between provinces

\begin{tabular}{lccc}
\hline Province & Total $(\boldsymbol{n}=170)$ & GPs $(\boldsymbol{n}=90)$ & \multicolumn{2}{c}{ MOs $(\boldsymbol{n}=80)$} \\
& $\boldsymbol{n}(\%)$ & $n(\%)$ & $12(15.0)$ \\
\hline Gauteng & $27(15.9)$ & $15(16.7)$ & $15(18.8)$ \\
Western Cape & $15(8.8)$ & $0(0.0)$ & $0(0.0)$ \\
Northern Cape & $12(7.1)$ & $12(13.3)$ & $18(22.5)$ \\
KwaZulu-Natal & $32(18.8)$ & $14(15.6)$ & $20(25.0)$ \\
Free State & $32(18.8)$ & $12(13.3)$ & $15(18.8)$ \\
Limpopo & $26(15.3)$ & $11(12.2)$ & $0(0.0)$ \\
North West & $14(8.2)$ & $14(15.6)$ & $0(0.0)$ \\
Mpumalanga & $12(7.1)$ & $12(13.3)$ & \\
\hline
\end{tabular}




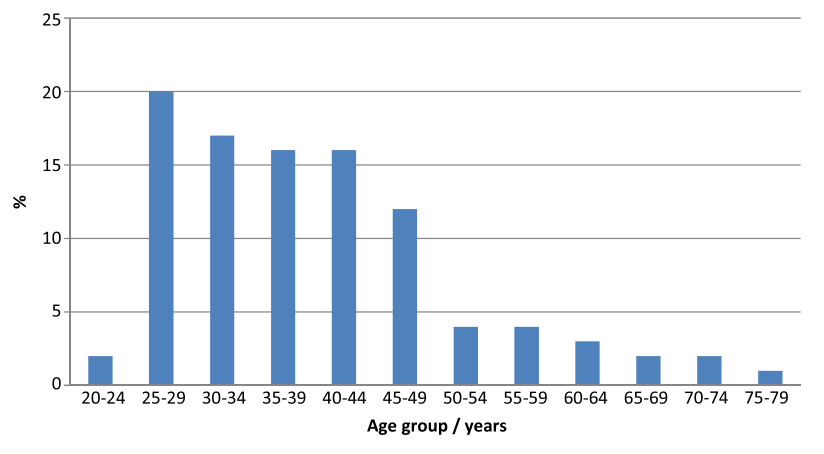

Figure 1: Age distribution of primary care doctors

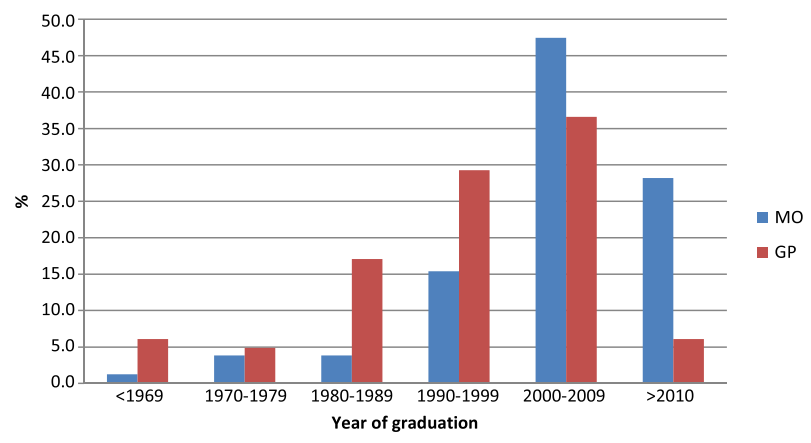

Figure 2: Distribution of medical officers (MOs) and general practitioners (GPs) by year of graduation

Table 3 shows the awareness of primary care doctors of key national primary care guidelines. Primary care doctors had only read the majority of the guidelines (20/30 scored 1.5-2.4), few were implemented in practice (6/30 scored between 2.5 and 3.4), and none felt able to teach others about any of the guidelines. Those that had been implemented included the national Standard Treatment Guidelines for PHC, the national TB management guidelines, the guidelines for STDs and the guidelines on HIV counselling, antiretroviral treatment and prevention of mother-to-child transmission. There was no awareness of the guidelines on paediatric advanced life support, advanced neonatal life support, managing patient complaints and primary health care facility supervision.

There were some significant differences between MOs and GPs. MOs were significantly more aware of the Standard Treatment Guidelines for PHC, guidelines on TB, Integrated Management of Childhood Illness guidelines, and emergency guidelines on basic, trauma and cardiovascular life support.

Table 4 shows the performance of key clinical skills by primary care doctors. All of the doctors had been trained in these clinical skills, but none of the doctors reported having taught these skills to others in the last year. Primary care doctors reported having performed the majority of the skills within the last year (70/85 score $2.50-3.49)$. Skills that had not been performed in the last year (15/85 score 1.50-2.49) included proctoscopy, performing a stress ECG, inserting an intrauterine contraceptive device, performing obstetric ultrasound, assessing child abuse, inserting an intra-osseous line, injecting tennis elbow or the sub-acromial space, cricothyroidotomy, cryotherapy/ cauterisation of skin lesions, trucut/punch biopsy of skin lesions, counselling a patient for a termination of pregnancy and using a genogram. Intrapartum skills were included as some primary care facilities have a midwife obstetric unit attached.
MOs were significantly more likely to have performed skills related to emergency care (e.g. femoral vein puncture, IV access in a child, insertion of an intra-osseous line, insert a urinary catheter, perform CPR, assess trauma, administer oxygen, insert a chest drain, measure the GCS), to have interpreted or performed their own investigations (e.g. radiographs, ECGs, pleural tap), to have used the Road To Health Card in children, to have certified a patient under the Mental Health Care Act, completed a Death Notification, shared bad news and used a genogram. GPs were significantly more likely to have injected a shoulder and repaired a third-degree tear during intra-partum care.

Table 5 shows the confidence of primary care doctors to perform the various roles. All of the doctors reported having taken on these roles at some time, although none felt confident enough to be a role-model in any of the areas for the PHC team. Doctors reported that they had performed $7 / 12$ roles in the last year, while $5 / 12$ had not been engaged with recently. The weakest roles were those of change agent and community advocate, while the strongest roles were competent clinician, capability builder and collaborator.

MOs and GPs showed very little difference in their confidence to perform these roles. The only role that showed a significant difference was that of making sense of information on the population served by the practice and sharing this with the $\mathrm{PHC}$ team, in which GPs felt significantly more confident.

\section{Discussion}

Primary care doctors were aware of the majority of key national guidelines relevant to primary care, but reported that very few had actually been adopted by them in clinical practice. In terms of the burden of disease there was implementation of guidelines related to HIV, TB and STDs, but other areas such as maternal and child health, non-communicable chronic diseases, and trauma or emergency care were poorly adopted. Most of the doctors had performed the necessary clinical skills within the last year and there were few reported gaps in their capability. Doctors were confident in their roles as clinicians, capability builders and collaborators, indicating that they felt competent clinically, saw themselves as mentors to nurse practitioners and able to work in collaborative multi-professional teams. Doctors were less confident to perform the roles of clinical governor, critical thinker and community advocate.

There were some important differences between the learning needs of MOs and GPs. GPs were less aware of guidelines related to life support and emergencies and less likely to have performed clinical skills related to emergency care in the last year. Upskilling their capability in emergency care would be a priority. GPs were also less aware of national guidelines related to TB management, probably because almost all such patients are managed in the public sector TB programme. Not surprisingly GPs were less aware of guidelines used exclusively in the public sector, such as the National Standard Treatment Guidelines based on the Essential Drug List. There was also low awareness amongst GPs of the Integrated Management of Childhood Illness guideline and use of the Road To Health Card, both of which form the backbone of clinical care for children under five years and strategies to reduce under-five mortality. On the other hand GPs felt more confident to interpret and share information on the community served with their healthcare team.

Efforts to strengthen PHC at a national level are focused on the contribution of primary care doctors to providing and improving 
Table 3: Awareness of key primary care guidelines amongst primary care doctors

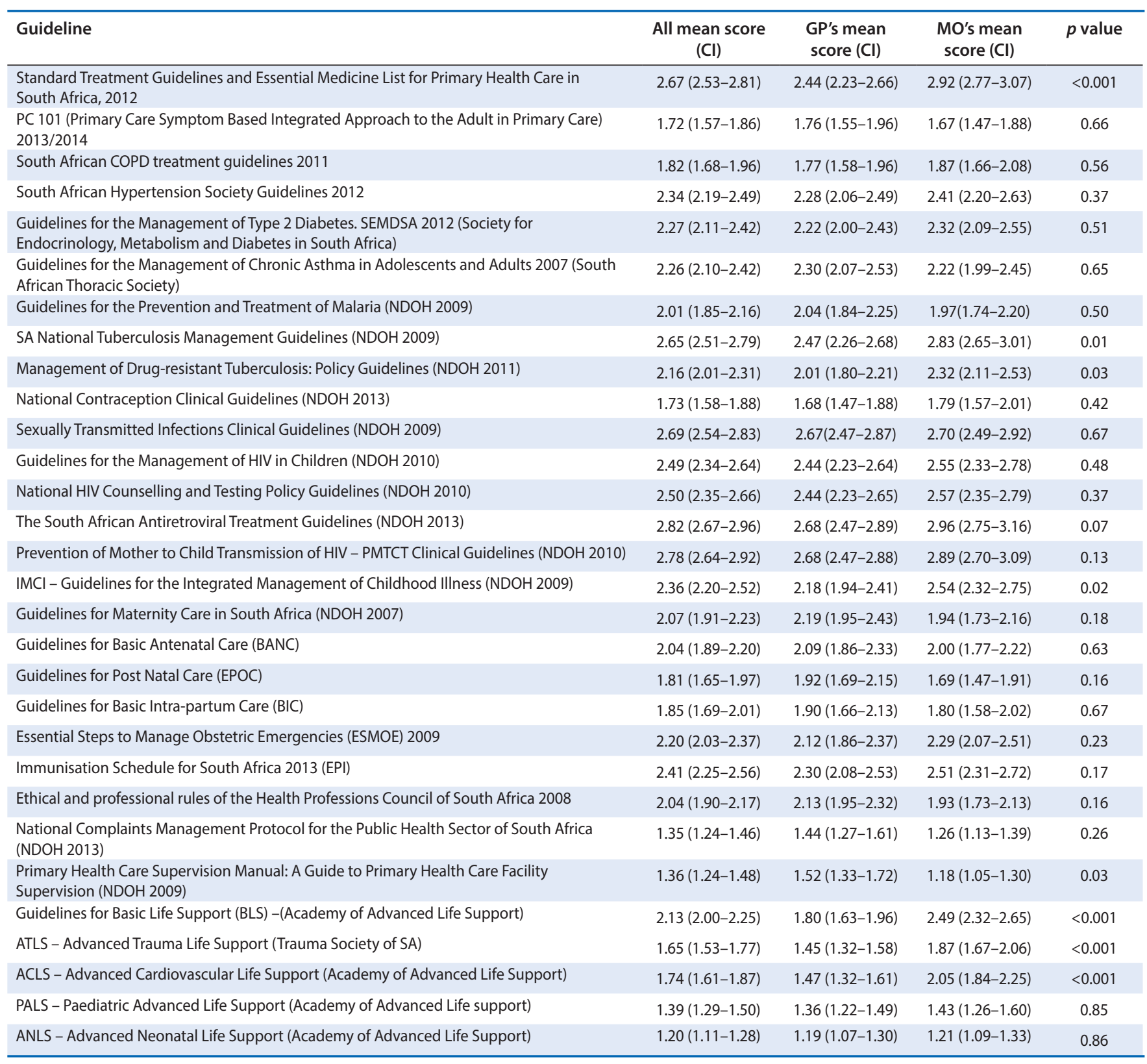

the quality of clinical care. There is emphasis on their role of clinical governance, although this study suggests that this is an area in which there are significant learning needs. The introduction of municipal ward-based outreach teams also relies on an orientation to the community served rather than the patient attending primary care facilities. ${ }^{5}$ Such community-orientated primary care is also an area with significant learning needs for primary care doctors, although the study suggests that GPs may be more orientated towards this than MOs. Several other studies have highlighted how COPC has largely been aspirational in African health systems. ${ }^{10,11}$

In order to make a difference to clinical practice, guidelines must not only be developed but also be contextualised, disseminated and actively implemented at the local level. ${ }^{12}$ Simply publishing the guideline is not sufficient to ensure implementation and few guidelines complete the whole process outlined above. The integration of individual adult guidelines into a single tool such as the PC101 guideline, ${ }^{13}$ which targets both nurses and doctors in the public sector, is an opportunity for more effective and efficient guideline implementation. Given the lack of active implementation following the publication of many guidelines it is not surprising that they appear to have had little impact on clinical practice.

The study has a number of limitations. The sample size was lower than desired, although it was sufficiently powered to still detect significant differences between MOs and GPs. The scores are selfreported and doctors may have overestimated their competency, particularly with regard to clinical skills and scope of practice. The GPs were selected from those interested in contracting with the public sector in NHI pilot districts and therefore may not be representative of all GPs. They were targeted, however, because they were actively considering their learning needs in terms of engaging with the broader primary healthcare system and therefore were motivated to complete the questionnaire. It is possible that the low scores obtained for some guidelines might reflect the resistance of primary care doctors to adopt guidelines that they consider out of date or not consistent with their practice. The fact that a clinical skill has recently been performed does not necessarily imply that the skill was performed competently and this could only be assessed by direct observation. 
Table 4: Performance of key clinical skills by primary care doctors

\begin{tabular}{|c|c|c|c|c|}
\hline Skill & All: mean score (Cl) & GP's mean score $(\mathrm{Cl})$ & MO's mean score $(\mathrm{Cl})$ & $p$ value \\
\hline \multicolumn{5}{|l|}{ General } \\
\hline Femoral vein puncture & $2.95(2.80-3.10)$ & $2.70(2.48-2.92)$ & $3.21(3.02-3.40)$ & $<0.001$ \\
\hline Intra-dermal injection & $3.03(2.88-3.17)$ & $3.04(2.85-3.23)$ & $3.01(2.78-3.23)$ & 0.95 \\
\hline Intra-muscular injection & $3.41(3.31-3.50)$ & $3.37(3.24-3.50)$ & $3.45(3.30-3.59)$ & 0.39 \\
\hline Subcutaneous injection & $3.32(3.21-3.43)$ & $3.36(3.22-3.50)$ & $3.28(3.11-3.46)$ & 0.79 \\
\hline Interpret chest $X$ ray & $3.42(3.30-3.53)$ & $3.27(3.10-3.45)$ & $3.57(3.43-3.71)$ & 0.02 \\
\hline Interpret abdominal $\mathrm{X}$ ray & $3.26(3.13-3.38)$ & $3.08(2.87-3.28)$ & $3.45(3.30-3.59)$ & 0.02 \\
\hline \multicolumn{5}{|l|}{ Abdomen } \\
\hline Proctoscopy & $1.64(1.51-1.77)$ & $1.7(1.51-1.89)$ & $1.57(1.40-1.74)$ & 0.46 \\
\hline \multicolumn{5}{|l|}{ Chest } \\
\hline Set up, record and interpret a stress ECG & $2.30(2.15-2.45)$ & $2.36(2.14-2.57)$ & $2.24(2.03-2.44)$ & 0.44 \\
\hline Set up, record and interpret a resting ECG & $2.92(2.78-3.06)$ & $2.64(2.45-2.83)$ & $3.22(3.03-3.41)$ & $<0.001$ \\
\hline Pleural tap & $3.12(2.99-3.26)$ & $2.90(2.70-3.09)$ & $3.36(3.19-3.53)$ & $<0.001$ \\
\hline Measure PEF (peak expiratory flow) & $2.73(2.59-2.87)$ & $2.74(2.54-2.93)$ & $2.73(2.52-2.93)$ & 0.85 \\
\hline Nebulise a patient & $3.30(3.18-3.41)$ & $3.14(2.97-3.31)$ & $3.46(3.32-3.61)$ & 0.01 \\
\hline Demonstrate use of inhalers and spacers & $3.28(3.15-3.40)$ & $3.11(2.93-3.29)$ & $3.46(3.30-3.62)$ & $<0.001$ \\
\hline \multicolumn{5}{|l|}{ Antenatal care } \\
\hline Plot and interpret antenatal growth chart & $2.93(2.80-3.07)$ & $2.91(2.72-3.11)$ & $2.96(2.76-3.15)$ & 0.76 \\
\hline Assess foetal movement/well-being & $2.87(2.74-3.01)$ & $2.91(2.73-3.10)$ & $2.83(2.62-3.04)$ & 0.62 \\
\hline Perform an obstetric ultrasound & $2.43(2.27-2.59)$ & $2.55(2.32-2.79)$ & $2.30(2.07-2.52)$ & 0.13 \\
\hline \multicolumn{5}{|l|}{ Intra-partum care } \\
\hline Examine progress during labour, plot and interpret partogram & $2.70(2.56-2.85)$ & $2.62(2.42-2.82)$ & $2.79(2.58-3.00)$ & 0.26 \\
\hline Apply and interpret CTG (cardiotocograph) & $2.68(2.52-2.83)$ & $2.52(2.32-2.73)$ & $2.84(2.62-3.06)$ & 0.05 \\
\hline Normal vaginal delivery & $2.66(2.52-2.79)$ & $2.61(2.42-2.80)$ & $2.70(2.51-2.89)$ & 0.52 \\
\hline Assisted vaginal delivery & $2.58(2.45-2.71)$ & $2.56(2.37-2.75)$ & $2.60(2.42-2.78)$ & 0.76 \\
\hline Episiotomy and suturing & $2.53(2.40-2.66)$ & $2.55(2.36-2.73)$ & $2.51(2.32-2.69)$ & 0.78 \\
\hline Repair of third-degree tear & $2.29(2.14-2.43)$ & $2.47(2.27-2.67)$ & $2.08(1.90-2.27)$ & 0.01 \\
\hline \multicolumn{5}{|l|}{ Post-partum/new born care } \\
\hline Resuscitate a newborn & $2.73(2.59-2.87)$ & $2.71(2.49-2.93)$ & $2.75(2.57-2.93)$ & 0.80 \\
\hline Teach a mother Kangaroo Care & $2.44(2.28-2.59)$ & $2.34(2.10-2.57)$ & $2.54(2.33-2.75)$ & 0.21 \\
\hline Well newborn check & $2.71(2.56-2.86)$ & $2.62(2.40-2.83)$ & $2.82(2.60-3.03)$ & 0.23 \\
\hline \multicolumn{5}{|l|}{ Women's health } \\
\hline Insert IUCD (intra-uterine contraceptive device) & $2.14(1.99-2.30)$ & $2.20(1.97-2.42)$ & $2.08(1.88-2.29)$ & 0.56 \\
\hline Cervical smear & $3.00(2.88-3.13)$ & $2.92(2.75-3.01)$ & $3.08(2.91-3.26)$ & 0.26 \\
\hline Drain a Bartholin cyst & $2.68(2.54-2.82)$ & $2.67(2.48-2.85)$ & $2.70(2.49-2.92)$ & 0.81 \\
\hline \multicolumn{5}{|l|}{ Paediatrics } \\
\hline Plot and interpret Road To Health booklet & $2.88(2.74-3.03)$ & $2.67(2.46-2.89)$ & $3.11(2.92-3.30)$ & $<0.001$ \\
\hline Assess child abuse: sexual/non-sexual & $2.47(2.33-2.62)$ & $2.39(2.18-2.59)$ & $2.57(2.35-2.78)$ & 0.28 \\
\hline Capillary blood sampling & $2.63(2.49-2.77)$ & $2.55(2.35-2.75)$ & $2.72(2.51-2.92)$ & 0.35 \\
\hline Developmental assessment & $2.71(2.57-2.85)$ & $2.62(2.42-2.81)$ & $2.80(2.60-3.01)$ & 0.24 \\
\hline IV access in a child & $2.96(2.83-3.10)$ & $2.70(2.51-2.90)$ & $3.25(3.09-3.41)$ & $<0.001$ \\
\hline Intra-osseous line & $2.47(2.31-2.63)$ & $2.28(2.06-2.50)$ & $2.67(2.45-2.89)$ & 0.02 \\
\hline \multicolumn{5}{|l|}{ Surgery/general adult health } \\
\hline Wound care dressings & $3.04(2.91-3.17)$ & $2.97(2.78-3.17)$ & $3.11(2.93-3.28)$ & 0.39 \\
\hline Suturing of laceration & $3.31(3.20-3.41)$ & $3.21(3.05-3.37)$ & $3.41(3.27-3.56)$ & 0.10 \\
\hline Insert urinary catheter & $3.23(3.11-3.34)$ & $3.08(2.91-3.24)$ & $3.39(3.25-3.54)$ & 0.01 \\
\hline Debride wounds and burns & $2.83(2.69-2.97)$ & $2.86(2.66-3.05)$ & $2.81(2.60-3.01)$ & 0.69 \\
\hline Perform a circumcision & $2.69(2.53-2.85)$ & $2.77(2.56-2.99)$ & $2.60(2.37-2.83)$ & 0.28 \\
\hline Administer a ring block & $2.91(2.77-3.05)$ & $2.77(2.57-2.98)$ & $3.06(2.87-3.25)$ & 0.08 \\
\hline Administer a regional block & $2.59(2.43-2.75)$ & $2.65(2.42-2.88)$ & $2.52(2.29-2.75)$ & 0.38 \\
\hline Incise and drain an abscess & $3.13(3.00-3.26)$ & $3.04(2.86-3.23)$ & $3.23(3.04-3.41)$ & 0.17 \\
\hline
\end{tabular}


Table 4: (Continued)

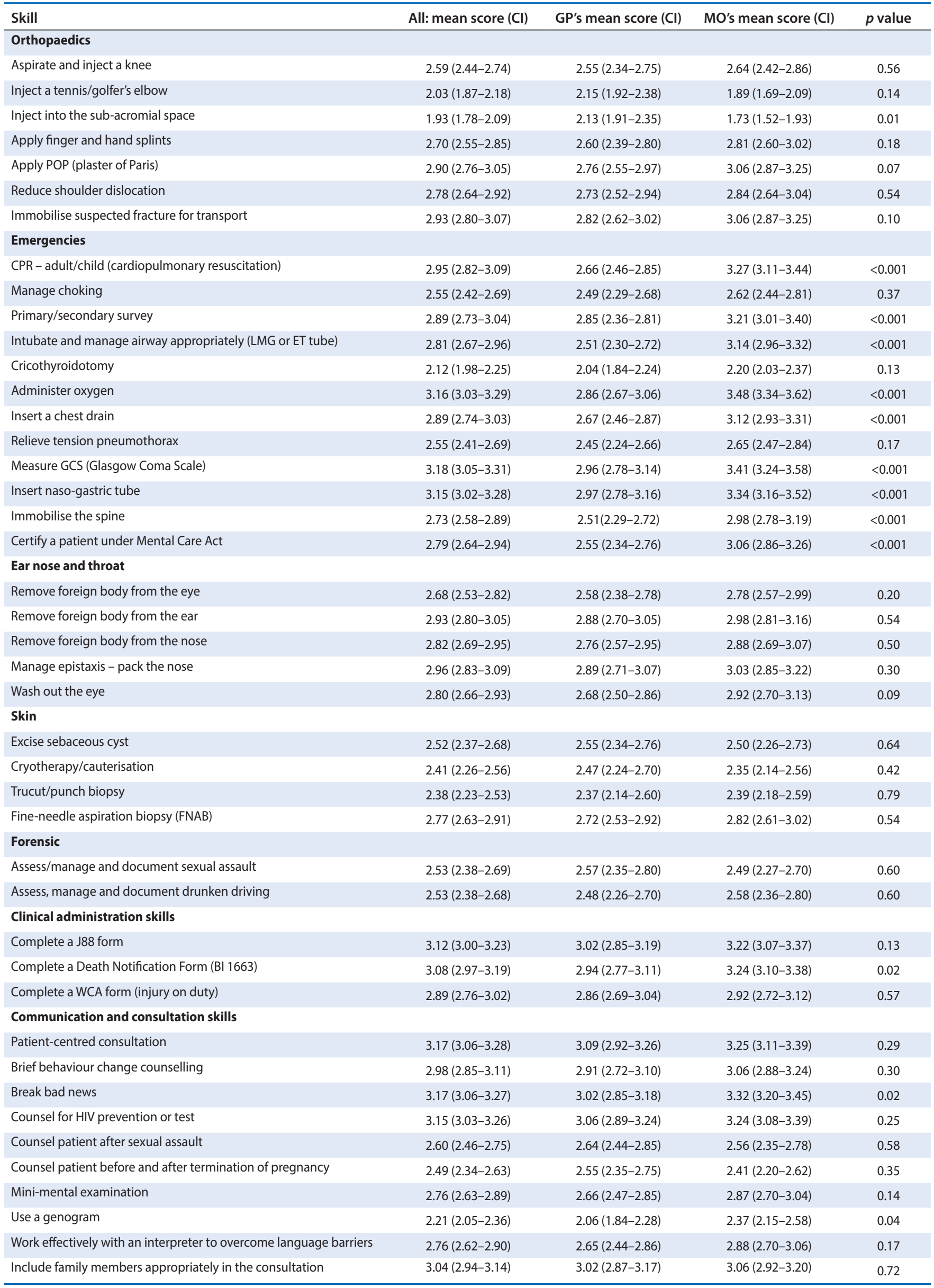


Table 5: Confidence of primary care doctors to perform roles across the full scope of practice

\begin{tabular}{|c|c|c|c|c|}
\hline & $\begin{array}{l}\text { All: mean score } \\
\qquad(\mathrm{Cl})\end{array}$ & $\begin{array}{l}\text { GP's mean score } \\
\text { (Cl) }\end{array}$ & $\begin{array}{l}\text { MO's mean } \\
\text { score }(\mathrm{Cl})\end{array}$ & $p$ value \\
\hline \multicolumn{5}{|l|}{ Competent clinician } \\
\hline Use a systematic, stepwise approach to solve ethical or professional dilemmas & $2.71(2.58-2.85)$ & $2.79(2.61-2.97)$ & $2.63(2.43-2.83)$ & 0.27 \\
\hline \multicolumn{5}{|l|}{ Clinical governance } \\
\hline Leading a quality improvement cycle for your team of primary care providers & $2.46(2.30-2.63)$ & $2.59(2.35-2.82)$ & $2.33(2.10-2.55)$ & 0.13 \\
\hline $\begin{array}{l}\text { Leading a meeting to critically reflect on deaths or significant adverse events in } \\
\text { your practice }\end{array}$ & $2.40(2.23-2.57)$ & $2.48(2.23-2.73)$ & $2.32(2.10-2.53)$ & 0.35 \\
\hline \multicolumn{5}{|l|}{ Critical thinker: } \\
\hline $\begin{array}{l}\text { Critically appraising and making recommendations for the incorporation of new } \\
\text { evidence in your primary care practice }\end{array}$ & $2.47(2.31-2.62)$ & $2.59(2.36-2.81)$ & $2.33(2.11-2.55)$ & 0.14 \\
\hline Helping staff in your team to interpret and use health indicators from your facility & $2.74(2.59-2.90)$ & $2.84(2.61-3.06)$ & $2.64(2.42-2.86)$ & 0.20 \\
\hline $\begin{array}{l}\text { Using referrals from clinical nurse practitioners as an opportunity to give them } \\
\text { feedback and provide supportive education }\end{array}$ & $2.96(2.83-3.10)$ & $3(2.81-3.18)$ & $2.93(2.73-3.12)$ & 0.61 \\
\hline $\begin{array}{l}\text { Providing continuing professional development or training to other primary care } \\
\text { providers }\end{array}$ & $2.77(2.61-2.92)$ & $2.78(2.56-3)$ & $2.76(2.53-2.98)$ & 0.84 \\
\hline \multicolumn{5}{|l|}{ Community advocate } \\
\hline $\begin{array}{l}\text { Helping community health workers to prioritise and respond appropriately to } \\
\text { issues discovered during home visits }\end{array}$ & $2.25(2.09-2.41)$ & $2.36(2.13-2.58)$ & $2.13(1.90-2.35)$ & 0.17 \\
\hline $\begin{array}{l}\text { Make sense of information on the population served by your practice and share } \\
\text { with others in the primary health care team }\end{array}$ & $2.41(2.25-2.58)$ & $2.59(2.36-2.82)$ & $2.21(1.98-2.44)$ & 0.02 \\
\hline \multicolumn{5}{|l|}{ Collaborator } \\
\hline Working collaboratively with other people in a multi-professional health care team & $3.12(2.99-3.26)$ & $3.09(2.88-3.30)$ & $3.16(2.99-3.32)$ & 0.87 \\
\hline
\end{tabular}

The findings of this study can help guide the curriculum development process for the Diploma in Family Medicine, which is aimed at helping primary care doctors to re-orientate and upskill themselves. ${ }^{14}$ Key implications are listed below:

- The curriculum should have enough flexibility to adapt to prior learning and focus on individual learning needs.

- Learning activities should be included that encourage the contextualisation and implementation of key guidelines in clinical practice.

- It should be ensured that the curriculum updates knowledge and skills for life support and emergency care.

- It should be ensured that GPs have the opportunity to familiarise themselves with TB management.

- It should be ensured that GPs have the opportunity to improve their interpretation of key investigations such as radiographs and ECGs.

- There should be a focus on building capability in the area of clinical governance. For example primary care doctors should be confident to initiate and facilitate quality improvement cycles, facilitate meetings to reflect on morbidity and mortality, support the supervision of PHC facilities and manage complaints. They should be able to interpret health information and research evidence and make it accessible to the team. They need skills in critical thinking and supporting reflection in the team.

- There should be a focus on building capability around community-orientated primary care. It is envisaged that doctors would support the municipal WBOTs by assisting them to make sense of information and plan responses at the level of the household or community. Critical thinking is again important to fulfil this role.

\section{Conclusions}

Primary care doctors reported that they are aware of key national primary care guidelines, but have not implemented many of them in their clinical practice. Doctors report that they have performed most of the required clinical skills in the last year. Doctors are confident in their roles as clinicians, capacity builders and collaborators, but less confident in their roles as clinical governors, community advocates and critical thinkers. There are a number of significant differences between the learning needs of MOs and GPs. These findings will help guide the development of new and revision of existing Diplomas in Family Medicine.

Acknowledgements - This study has been conducted with the financial assistance of the European Union. The contents of this document are the sole responsibility of the authors and can under no circumstances be regarded as reflecting the position of the European Union.

The induction and orientation workshops, at which data were collected from GPs, were funded by the UK Department of International Development (DFID) through the SARRAH project (Strengthening South Africa's response to HIV and Health).

The authors offer thanks to D. O'Mahoney (Walter Sisulu University), M. Naidoo (University of KwaZulu-Natal, J. Blitz (Stellenbosch University) and members of the Health Professional National Technical Task Team, led by the Deputy Director General of Primary Health Care, J. Hunter, who helped to validate the questionnaire.

The authors are also grateful to the following individuals: V. Kruger, D. Morran, T. Patterson and N. James from the SARRAH project, N. Mofolo (Free State University), I. Govender (University of Limpopo, Medunsa Campus), G. Botha (Pretoria University) and M. Naidoo (University of KwaZulu-Natal) who assisted with data collection.

Dr J. Harvey from the Centre for Statistical Consultation at Stellenbosch University who assisted with the analysis. 
The following members of the SA Academy of Family Physicians' Education and Training Committee who reflected on the results of the survey at a national workshop: J. Blitz (Stellenbosch University), G. Bresick and B. Schweitzer (University of Cape Town), N. Mofolo and H. Steinberg (Free State University), I. Couper and L. Baldwin-Ragaven (University of Witwatersrand), G. Botha and S. Smith (Pretoria University), I. Govender and H. Mabuza (University of Limpopo), M. Naidoo and C. Rangiah (University of KwaZulu-Natal), P. Yogeswaran and J. Chandia (Walter Sisulu University), and J. Morgan (Registrar).

\section{References}

1. Department of Health. National health insurance in South Africa: policy Paper. Pretoria: Department of Health; 2011.

2. Mash B, Fairall L, Adejayan O, et al. A morbidity survey of South African primary care. PLoS One. 2012;7(3):1-12. http://dx.doi.org/10.1371/ journal.pone.0032358

3. Rispel L, Moorman J, Chersich M, et al. Revitalising primary health care in South Africa: review of primary health care package, norms and standards. Johannesburg: Centre for Health Policy, School of Public Health, Wits University; 2010. p. 33-60.

4. Matsoso MP, Fryatt B. National Health Insurance: the first 18 months. In: Padarath A, English R, editors. South African Health Review 2012/13. Durban: Health Systems Trust; 2013. p. 21-33.

5. Bam N, Marcus T, Hugo J, et al. Conceptualizing community oriented primary care (COPC)-the Tshwane, South Africa, health post model. Afr Journal Prim Health Care Fam Med. 2013; 5(1):3 p.

6. Fryatt B, Hunter J, Matsoso MP. Innovations in primary health care: considerations for National Health Insurance. In: Padarath A, English R, editors. South African Health Review 2013/14. Durban: Health Systems trust; 2014. p. 33-44.
7. South African Academy of Family Physicians. A national position paper on family medicine. 2014 [cited 2014 Oct 11]; Available from: http:// www.saafp.org/.

8. Mash R. The roles and competencies required of the future primary care doctor: Summary of a national stakeholders workshop. 2014 [cited 2014 Oct 11]; Available from: http://www.sun.ac.za/english/ faculty/healthsciences/Family\%20Medicine $\% 20$ and $\% 20$ Primary $\% 20$ Care/Pages/National-Stakeholder-workshop.aspx

9. Couper ID, Mash B. Obtaining consensus on core clinical skills for family medicine training. S Afr Fam Pract. 2008;50(6):69-73.

10. Mash R, Downing R, Moosa S, De Maeseneer J. Exploring the key principles of family medicine in sub-Saharan Africa: international Delphi consensus process. S Afr Fam Pract. 2008;50(3):60-65. http:// dx.doi.org/10.1080/20786204.2008.10873720

11. Reid SJ, Mash R, Downing RV, et al. Perspectives on key principles of generalist medical practice in public service in sub-Saharan Africa: a qualitative study. BMC Fam Pract. 2011;12:1-9, 2296-12-67. http:// dx.doi.org/10.1186/1471-2296-12-67

12. Francke $A L$, Smit $M C$, De Veer $A J$, et al. Factors influencing the implementation of clinical guidelines for health care professionals: a systematic meta-review. BMC Med Inform Decis Mak. 2008;8:1-11,69478-38. http://dx.doi.org/10.1186/1472-6947-8-38

13. Knowledge Translation Unit. Primary care 101: symptom-based integrated approach to the adult in primary care - South Africa. 2014 [cited 2014 Oct 11]; Available from: http://knowledgetranslation.co. za/programmes/pc-101/.

14. Education and Training Committee. Design of a national diploma in family medicine: workshop with the education and training committee of theSAacademy offamily physicians.2014 [cited 2014Oct 11]; Available from: http://www.sun.ac.za/english/faculty/healthsciences/ Family\%20Medicine\%20and\%20Primary\%20Care/Pages/EuropeAid. aspx. 